\title{
Developing a Novel Resilience Curriculum for Internal Medicine Interns Using a Survey-Based Needs Assessment
}

$\mathrm{J}$ Gen Intern Med 36(5):1451-3

DOI: $10.1007 / \mathrm{s} 11606-020-05870-7$

(c) Society of General Internal Medicine 2020

\section{INTRODUCTION}

The highest rates of burnout syndrome, defined as emotional exhaustion, depersonalization, and reduced personal accomplishment, are found in residents and fellows, and burnout may lead to increased medical errors. ${ }^{1,2}$ Internal medicine residents with burnout are more likely to report providing suboptimal care to patients when compared with nonburnout peers. ${ }^{3}$

Although there have been campaigns to create residency curricula that promote resilience, ${ }^{4,5}$ improvement of burnout metrics with curricular interventions has not been strongly demonstrated. We hypothesized that resident resilience metrics would improve with implementation of a tailored resilience curriculum based on a needs assessment of internal medicine interns.

\section{METHODS}

We enrolled all internal medicine and medicine-pediatric interns at the University of Colorado School of Medicine during the 2017-2018 academic year. An anonymous survey-based needs assessment was administered to all interns at the beginning of the academic year. The needs assessment included 5point Likert scale questions on personal and professional stress management, burnout, and perceptions of program support of housestaff. Based on the needs assessment survey results, a five-part resilience curriculum was designed by chief residents and vetted by resident and faculty members of the residency wellness committee. Each 30-minute curriculum session, facilitated by senior residents and faculty, was executed during consecutive educational half-days from November 2017 to May 2018. A post-intervention survey with the same questions as the initial needs assessment was administered to all interns at the conclusion of the curriculum. Data were analyzed using SAS Enterprise Guide 7.1 (SAS Institute, Inc., Cary, NC).

Previous Presentations The descriptive statistics in this dataset were presented as a poster at the Education Scholarship \& Innovation Symposium at the University of Colorado Anschutz Medical Campus on May 13, 2019.

Received March 5, 2020

Accepted April 22, 2020

Published online September 8, 2020
Survey questions were organized into four domains (selfperceptions of wellness, coping mechanisms, professional identity, and organizational culture). Questions with the greatest change in distribution from pre- to post-survey were tested statistically using Fisher's exact test.

\section{RESULTS}

Of 80 total interns, 58 completed the pre-survey (72.5\%) and 52 completed the post-survey $(65 \%)$. The survey results are displayed in Table 1.

In the self-perceptions of wellness domain, greater than $70 \%$ of interns indicated they felt burnout; this value did not significantly change between the pre- and post-surveys. There was a statistically significant increase in the coping mechanisms domain of having an outlet in the residency program to discuss professional stress, which increased from 59 to $87 \%$ $(p=0.0014)$. In the professional identity domain, there was a significant increase in feeling camaraderie with fellow residents ( 86 to $98 \%, p=0.0340$ ) and a near-significant increase in perception that burnout management skills are best learned from other residents ( 40 to $59 \%, p=0.0559$ ). In the organizational culture domain, there was a near-significant increase in the perception that the residency program promotes wellness, from 66 to $83 \%(p=0.0519)$.

\section{DISCUSSION}

We present a novel resilience curriculum that was designed using a survey-based needs assessment of internal medicine interns. Implementation of our curriculum resulted in significantly increased reporting of an outlet in the residency program to discuss professional stress, as well as increased perception that the residency program promotes wellness. We hypothesize that increased exposure of interns to senior residents and faculty who executed the curriculum resulted in this perceptual change. The presence of the curriculum itself may also have induced an institutional paradigm shift towards a more resilience-focused program.

The increase in perception that burnout skills are best learned from other residents approached significance in our study, which suggests that culture among housestaff, independent of interventions of residency leadership, may be an important component of resident wellness. This hypothesis is bolstered by the significant increase we found in camaraderie among residents after our curricular intervention. 
Table 1 Comparison of Pre-Survey and Post-Survey Likert Results with Chi-Square Analyses

\begin{tabular}{|c|c|c|c|c|}
\hline Self-perceptions of wellness & $\begin{array}{l}\text { Pre-survey, } N \text { (\% } \\
\text { agree) } \\
N=58\end{array}$ & $\begin{array}{l}\text { Post-survey, } N \text { (\% } \\
\text { agree) } \\
N=52\end{array}$ & $\begin{array}{l}p \\
\text { value }\end{array}$ & $\begin{array}{l}\text { Difference }(95 \% \\
\text { CI) }\end{array}$ \\
\hline Overall, I feel physically well as a resident physician. & $42(72)$ & $39(75)$ & & \\
\hline Overall, I feel emotionally well as a resident physician. & $42(72)$ & $36(69)$ & & \\
\hline I have the skills necessary to manage my professional stress. & $48(83)$ & $46(88)$ & & \\
\hline $\begin{array}{l}\text { I manage my stress best: } \\
\text { In a group setting }\end{array}$ & $17(29)$ & $15(30)$ & 0.5084 & $N / A$ \\
\hline $\begin{array}{l}\text { On my own } \\
\text { Both }\end{array}$ & $\begin{array}{l}36(62) \\
5(9)\end{array}$ & $\begin{array}{l}27(54) \\
8(16)\end{array}$ & & \\
\hline \multirow[t]{2}{*}{ I never or rarely feel burnout. } & $13(22)$ & $15(29)$ & 0.5133 & $\begin{array}{l}0.06(-0.10 \\
0.24)\end{array}$ \\
\hline & $N$ (\% disagree) & $N$ (\% disagree) & $\begin{array}{l}p \\
\text { value }\end{array}$ & $\begin{array}{l}\text { Difference }(95 \% \\
\text { CI) }\end{array}$ \\
\hline $\begin{array}{l}\text { I feel more insensitive or callous towards others as I go through } \\
\text { residency. }\end{array}$ & $20(34)$ & $21(40)$ & & \\
\hline I feel depression or sadness regarding my work in residency. & $35(60)$ & $34(65)$ & & \\
\hline I cannot remember why I wanted to become a physician. & $48(83)$ & 37 (71) & 0.1752 & $\begin{array}{l}0.12(-0.04 \\
0.28)\end{array}$ \\
\hline I feel inferior or inadequate to my fellow residents. & $23(40)$ & $28(54)$ & 0.1802 & $\begin{array}{l}0.14(-0.33 \\
0.05)\end{array}$ \\
\hline Coping mechanisms & $\begin{array}{l}\text { Pre-survey, } N(\% \\
\text { agree })\end{array}$ & $\begin{array}{l}\text { Post-survey, } N(\% \\
\text { agree) }\end{array}$ & $\begin{array}{l}p \\
\text { value }\end{array}$ & $\begin{array}{l}\text { Difference }(95 \% \\
\text { CI) }\end{array}$ \\
\hline I have an outlet in my personal life to discuss professional stress. & $51(88)$ & $47(90)$ & & \\
\hline $\begin{array}{l}\text { I have an outlet in the residency program to discuss professional stress. } \\
\text { I use writing as a way to manage my professional stress. }\end{array}$ & $34(59)$ & $45(87)$ & 0.0014 & $0.28(0.100 .44)$ \\
\hline $\begin{array}{l}\text { 1 use meditation techniques as a way to manage my professional stress. } \\
\text { I use exercise as a way to manage my professional stress. }\end{array}$ & $\begin{array}{l}13(26) \\
37(64)\end{array}$ & $\begin{array}{l}18(35) \\
37(71)\end{array}$ & & \\
\hline I use spiritual or religious practices to manage my professional stress. & $10(17)$ & $8(15)$ & & \\
\hline $\begin{array}{l}\text { I would like to learn skills to help me become more emotionally present } \\
\text { and mindful with my professional work. }\end{array}$ & $33(57)$ & $28(54)$ & & \\
\hline $\begin{array}{l}\text { I would be interested in small group sessions to discuss ways to manage } \\
\text { stress. }\end{array}$ & $24(41)$ & $20(38)$ & & \\
\hline Professional identity & $\begin{array}{l}\text { Pre-survey, } N(\% \\
\text { agree })\end{array}$ & $\begin{array}{l}\text { Post-survey, } N(\% \\
\text { agree) }\end{array}$ & $\begin{array}{l}p \\
\text { value }\end{array}$ & $\begin{array}{l}\text { Difference }(95 \% \\
\text { CI) }\end{array}$ \\
\hline I feel fulfillment in the work that I do in residency. & $44(76)$ & $46(88)$ & 0.1363 & $\begin{array}{l}0.12(-0.02 \\
0.27)\end{array}$ \\
\hline $\begin{array}{l}\text { When I am with patients, I feel that I can be emotionally present with } \\
\text { them. }\end{array}$ & $46(79)$ & $41(79)$ & & \\
\hline I feel a strong sense of camaraderie with my fellow residents. & $50(86)$ & $51(98)$ & 0.0340 & $0.12(0.02,0.24)$ \\
\hline Skills for managing stress and burnout can be taught. & 43 (74) & $41(79)$ & & \\
\hline $\begin{array}{l}\text { Skills for managing stress and burnout are best learned from other } \\
\text { residents. }\end{array}$ & $23(40)$ & $30(59)$ & 0.0559 & $\begin{array}{l}0.19(-0.00 \\
0.37)\end{array}$ \\
\hline $\begin{array}{l}\text { Skills for managing stress and burnout are best learned from faculty and } \\
\text { residency leadership. }\end{array}$ & $20(35)$ & $18(35)$ & & \\
\hline \multirow{2}{*}{$\begin{array}{l}\text { Professional stress never interferes with my personal life and } \\
\text { relationships outside of my work. }\end{array}$} & $5(9)$ & $6(12)$ & & \\
\hline & $N(\%$ disagree $)$ & $N$ (\% disagree) & $\begin{array}{l}p \\
\text { value }\end{array}$ & $\begin{array}{l}\text { Difference }(95 \% \\
\text { CI) }\end{array}$ \\
\hline $\begin{array}{l}\text { I feel less enthusiastic about my professional work as I go through } \\
\text { residency. }\end{array}$ & $14(24)$ & $16(31)$ & & \\
\hline I feel that professional stress interferes with how I care for my patients & $15(26)$ & $17(33)$ & & \\
\hline Organizational culture & $\begin{array}{l}\text { Pre-survey, } N(\% \\
\text { agree })\end{array}$ & $\begin{array}{l}\text { Post-survey, } N(\% \\
\text { agree) }\end{array}$ & $\begin{array}{l}p \\
\text { value }\end{array}$ & $\begin{array}{l}\text { Difference }(95 \% \\
\text { CI) }\end{array}$ \\
\hline Our residency program promotes wellness. & $38(66)$ & 43 (83) & 0.0519 & $0.17(0.00,0.33)$ \\
\hline My fellow residents promote wellness in this program. & $45(78)$ & $44(86)$ & 0.3228 & $0.9(-0.07,0.23)$ \\
\hline The faculty in our residency promote wellness. & $38(66)$ & $38(73)$ & & \\
\hline $\begin{array}{l}\text { It is important to have an outlet with our residency program to discuss } \\
\text { stress. }\end{array}$ & $52(90)$ & $47(90)$ & & \\
\hline $\begin{array}{l}\text { I feel comfortable speaking with fellow residents about my professional } \\
\text { stress. }\end{array}$ & $43(74)$ & $45(87)$ & 0.1516 & $\begin{array}{l}0.12(-0.03 \\
0.27)\end{array}$ \\
\hline The culture that the administration creates is important in my wellness. & $48(83)$ & $45(87)$ & & \\
\hline The culture that my fellow residents create is important in my wellness. & $54(93)$ & $52(90)$ & & \\
\hline I have received training on burnout during medical school. & $36(62)$ & N/A & & \\
\hline
\end{tabular}

For positively worded questions, "disagree" includes responses of 1, 1.5, 2, 2.5, 3, and 3.5, and "agree" includes responses of 4, 4.5, and 5. For negatively worded questions, "disagree" includes responses of 1, 1.5, and 2; "neutral" includes responses of 2.5, 3, and 3.5; and "agree" includes responses of 4, 4.5, and 5. P values are included for all a priori comparisons, italicized above.

It is important to note that burnout and wellness indicators in the self-perceptions of wellness domain did not significantly change after execution of the resilience curriculum. This finding is consistent with previously published reports, as prior studies have not demonstrated improvements in burnout scores with residency curriculum interventions. ${ }^{6}$

Our study is a single-center intervention and therefore may be limited in its external validity. Further, the finding of near- 
significant $p$ values implies that a larger cohort may have increased the power of our study to demonstrate statistical significance. We did not use a validated burnout instrument in our pre- and post-intervention surveys, and pre-post survey studies cannot account for temporal confounders. Further studies on how to optimally implement resilience curricula are warranted.

Ajay Major, MD, MBA

Section of Hematology and Oncology, University of Chicago Medicine,

Chicago, IL, USA

John G. Williams, MD

Division of Pulmonary and Critical Care Medicine,

University of Maryland Medical Center,

Baltimore, MD, USA

Geoffrey R. Connors, MD

Division of Pulmonary and Critical Care Medicine,

University of Colorado School of Medicine,

Aurora, CO, USA

Lauren McBeth, BA

Angela Keniston, MSPH

Roxana Naderi, MD

Division of Hospital Medicine, University of Colorado School of Medicine,

Aurora, CO, USA

Corresponding Author: Roxana Naderi, MD; Division of Hospital Medicine, University of Colorado School of Medicine Aurora, CO, USA (e-mail: e-mail: roxana.naderi@cuanschutz.edu).

Contributors There are no other contributors to report.

\section{Compliance with Ethical Standards:}

This study adhered to institutional ethical standards set by the University of Colorado.

Conflict of Interest: The authors declare that they do not have a conflict of interest.

IRB Statement: This study was deemed "Not Human Subject Research" by the University of Colorado Multiple Institutional Review Board (COMIRB 17-2439).

\section{REFERENCES}

1. Dyrbye LN, West CP, Satele D, Boone S, Tan L, Sloan J, Shanafelt TD. Burnout among U.S. medical students, residents, and early career physicians relative to the general U.S. population. Acad Med. 2014;89(3):443-451. https://doi.org/10.1097/ACM.0000000000000134.

2. Dyrbye L, Shanafelt, T. A Narrative review on burnout experienced by medical students and residents. Med Educ. 2016;50(1):132-149. https:// doi.org/10.1111/medu.12927.

3. Shanafelt TD, Bradley KA, Wipf JE, Back AL. Burnout and self-reported patient care in an internal medicine residency program. Ann Intern Med. 2002;136(5):358. https://doi.org/10.7326/0003-4819-136-5200203050-00008.

4. Aggarwal R, Deutsch J, Medina J, Kothari N. Resident wellness: an intervention to decrease burnout and increase resiliency and happiness. MedEdPORTAL Publ. 2017;13. https://doi.org/10.15766/mep_23748265.10651.

5. Arnold J, Tango J, Walker I, Waranch C, McKamie J, Poonja Z, Messman A. An evidence-based, longitudinal curriculum for resident physician wellness: the 2017 Resident Wellness Consensus Summit. West J Emerg Med.2018;19(2):337-341. https://doi.org/10.5811/westjem. 2017.12.36244.

6. Bird A-N, Martinchek M, Pincavage AT. A curriculum to enhance resilience in internal medicine interns. J Grad Med Educ. 2017;9(5):600604. https://doi.org/10.4300/JGME-D-16-00554.1.

Publisher's Note: Springer Nature remains neutral with regard to jurisdictional claims in published maps and institutional affiliations. 